\title{
Applications of fuzzy logic for determining the driving forces in collaborative research contracts
}

Jasmina Berbegal-Mirabent, Universitat Internacional de Catalunya

Carlos Llopis-Albert, Universitat Politècnica de València

Send correspondence to Jasmina Berbegal-Mirabent, Universitat Internacional de Catalunya, Department of Economy and Business Organization, C. Immaculada, 22, Barcelona 08017, Spain (jberbegal@uic.es); Carlos Llopis-Albert, Universitat Politècnica de València, Departamento de Ingeniería Mecánica y de Materiales (DIMM), Camino de Vera s/n, Valencia 46022, Spain (cllopisa@upvnet.upv.es). 


\begin{abstract}
This study examines various factors (human capital, experience, attraction capacity, and profile) of technology centers that, according to the literature, affect the performance of science-industry R\&D partnerships. The measure of performance is the income that $R \& D$ contracts generate divided by the number of clients that the research center has. The data sample considers technology centers operating in the region of Catalonia that act under the TECNIO umbrella brand. The analysis uses fsQCA methodology, which allows identifying a combination of causes that lead to the outcome. Results support the argument that different causal paths explain profitable $\mathrm{R} \& \mathrm{D}$ contracts.
\end{abstract}

Keywords: Science-industry partnerships; R\&D contracts; technology centers; fsQCA 


\section{Introduction}

R\&D activities are of strategic importance for the innovative performance of firms (Howells et al., 2008). The organization of these activities can be either internal or external to the firm. According to the literature of open innovation (Chesbrough, 2003), firms need to open themselves up to external knowledge relations to gain new and fresh ideas that allow them to innovate and leverage markets. No company is smart enough to know exactly what to do with every new opportunity; and no company has enough resources to pursue all the opportunities that the firm might execute (Wolpert, 2002).

Because research institutions are relevant knowledge-intensive organizations, research portrays the establishment of collaborative science-industry partnerships as one of the primary means by which firms can gain access to and acquire significant knowledge (Spithoven \& Teirlinck, 2014). Such alliances reinforce the idea that firms might not conduct all R\&D activities internally, forcing them to expand and look outside their own boundaries to complement their in-house R\&D efforts (Lin, 2014).

R\&D alliances materialize in a variety of forms (Odagiri, 2003). For the purpose of this study, the terms "R\&D partnerships" and "R\&D alliances" designate an R\&D agreement by which a firm contractually pays a research institution to perform $R \& D$ activities.

From the standpoint of firm capabilities, external and internal R\&D complement each other (Lee et al., 2007; Ribeiro \& Castrogiovanni, 2012). Firms tend to outsource R\&D activities in which they are not specialists, but which may still be important as support (Kogut \& Zander, 1992); in this way, firms can concentrate on those tasks they do best (Narula, 2001). However, the outsourcing of more core-related R\&D activities may also be beneficial, as external resources and knowledge can close the gaps in firms' internal capabilities (Kang et al., 2012). 
Several studies report the benefits arising from collaborative science-industry agreements (Teirlinck \& Spithoven, 2013). First, these partnerships are imperative for the firm because partnerships facilitate knowledge acquisition and exploitation of novel scientific discoveries, the possibility to complement firms' scarce internal resources, and the opportunity to enlarge firms' social networks (Audretsch et al., 2012). Second, science-based institutions need the industry's knowledge of the market to come up with new, applicable, and successful technology developments (Ribeiro \& Urbano, 2010). Furthermore, such collaborations gain research centers' additional funding support, which is fundamental to safeguarding the viability of future research endeavors (Baba et al., 2009; Lai, 2011).

Although research institutions encompass different types of centers, the vast majority of previous works analyzing science-industry R\&D alliances restrict their analysis to research institutions that belong or hold affiliation to a university (Bruneel et al., 2010; Perkmann et al., 2011). Aiming at covering this research gap, this study posits that both university-affiliated and non-affiliated research institutions can achieve successful R\&D science-industry partnerships, although these institutions might follow different paths. Accordingly, this study examines how the profile of the research institution in combination with other factors that the literature lists as determinants for R\&D partnership (namely, human capital, experience, and attraction capacity) affect the performance of such alliances.

The data sample considers as research institutions the technology centers (TCs) operating in the region of Catalonia (Spain) that act under the TECNIO umbrella brand. As a measure of performance, the empirical application considers the income resulting from R\&D contracts per client. A configurational comparative method, fsQCA, allows meeting this objective. The findings suggest that although university-affiliated TCs may 
have different ways that lead to productive $R \& D$ partnerships, non-affiliated centers can also obtain some causal paths.

\section{Theoretical underpinnings}

Literature on science-based collaborative R\&D partnerships suggests different factors that help explain the performance of such alliances. An in-depth description and discussion of each of these factors follows.

\subsection{Human capital}

Research portrays organizations that are intensive in scientific and technical human capital as the ideal partners for collaborative R\&D activities. Although research institutions usually have advanced facilities and machinery that require a considerable investment and are only available to very few companies, highly skilled human capital resources that these institutions possess are what really makes them attractive for firms. Indeed, because nothing can take away knowledge from individuals, knowledge, abilities, and capabilities constitute key determinants for firms when those firms look for their R\&D partner. Thus, the higher the research institution's level of expertise, the greater the institution's ability to attract firms. Therefore, the skill composition of the academic board of a research institution seems to play an important role (Feng et al., 2012). This hypothesis is consistent with the idea that researchers with a greater level of human capital are intellectually mature, which in turn may lead to a greater facility for developing fresh ideas, building new knowledge, and establishing stronger working networks. 
Accordingly, the availability of qualified human resources at research institutions might act as a catalyst, attracting firms' interest for the establishment of fruitful R\&D partnerships.

\subsection{Experience}

Previous experience gives people the specific knowledge and capabilities that can help them develop successful strategies. On the one hand, the effective implementation of the knowledge stock can represent the starting point for future advances, reducing the time spans necessary to develop new activities (Anderson et al., 2007). On the other hand, experience captures the dynamic knowledge spillovers resulting from past activities, which develop appropriate managerial capabilities that facilitate the production of outputs in the present.

One way to account for experience is measuring how active the research institution is in conducting cutting-edge advances. According to economic and sociological theories, external perceptions of an organization's current performance affect the probability of potential buyers to transact with that organization (Weigelt \& Camerer, 1988; Wilson, 1985). In the context of science-industry alliances, a firm's decision to ally with a university depends on academic performance (Laursen et al., 2011; Sine et al., 2003; Soh \& Subramanian, 2013). Because knowledge generation entails some degree of uncertainty, firms will be more willing to transact with research institutions that have a more solid reputation (Kathoefer \& Leker, 2012; Sine et al., 2003). If research achievements have an impact within the scientific community, the capacity of the research institution to generate firm awareness will increase, thereby enhancing the likelihood that firms will know about that organization. 
Consistent with previous studies, this study argues that experience in the form of records of accomplishment and historical successes is key to attract funding and partners; hence, experience positively contributes to more profitable R\&D partnerships. For the purpose of this study, experience takes the form of patents and publications. Both patents and publications capture the quality of this research and stimulate future research activity (Mowery et al., 2002).

In the case of patents, researchers willing to apply for a patent receive the assessment of their research institution about the possibilities of the technology, and must pass different stages that guarantee the quality and uniqueness of their invention. Only those invention disclosures that successfully pass all controls continue with the process. In the next stage, a public organism performs a second evaluation of the suitability of patenting the technology. This process is much more strict and complex than the former. Thus, the patenting activity is an appropriate proxy for the quality and the potential applicability of the research.

The case of articles' publication in academic journals is similar. According to Kao and Hung (2008), publications in well-known indexed journals not only reflect quantity but also quality aspects of the research. This role of articles is possible because researchers submit papers to journals with a blind-peer review system and journals publish those papers following the quality standards of the academia. Thus, restricting the research productivity to only those scientific articles appearing in top journals is a suitable approach.

\subsection{Attraction capacity}

Because the marketing function is fundamental for finding new partners, researchers have to take either a direct or an indirect role in promoting the quality of the 
research activities that takes place within their centers. However, although scientists are very competent in providing new knowledge and technological advances, how to market best their research results is usually outside their experience (Gray, 2011).

From a relationship marketing perspective, advertising is an activity of the organization rather than the function of a particular unit (Rivers \& Gray, 2013). Although researchers need to participate in this process of advertising, a specific unit or technical staff in charge of marketing activities is paramount to ensure the visibility of the research center. Research institutions can use different formulas to accomplish this purpose. Publishing and patenting are a first step; however, research institutions need to develop appropriate marketing strategies aiming at communicating, delivering, and exchanging offerings with potential value for partners.

Although prior studies suggest that informal networks are sufficient to trigger future successful science-industry relationships (Kreiner \& Schultz, 1993; Liebeskind et al., 1996), complementary strategies are necessary to capture firms' attention (Batonda \& Perry, 2003). By scanning the environment and targeting potential partners, this study proposes that further strategies need to concentrate on generating firms' awareness, and converting this awareness into new customers.

Research shows that a combination of different communication channels, including both social networking and transactional marketing approaches, are effective methods for identifying prospects; hence, these methods are appropriate mechanisms for spreading the activities that research institutions carry and, more importantly, for making publicly available their technological portfolio offer. Efforts are effective if they translate into new customers. Sustaining a long-term partnership is the final objective.

\subsection{Profile of the research institution}


Affiliation with a university. Previous research on science-industry R\&D alliances mainly concentrates on university-industry partnerships. Literature evidences the multiple benefits that firms obtain from partnering with a university (Lee \& Win, 2004). Universities facilitate firms' access to a wide array of human capital, knowledge, and innovation networks. Universities also offer their infrastructures and equipment. Furthermore, universities help firms identify technological opportunities, and assist in pre-competitive stages of product development. However, although independent research institutions can also undertake all these actions (affiliation to a university not being a prerequisite), potential partners may think that all these advantages can easier to achieve if the research institution has existing ties and a formal entailment with a university (Van Looy et al., 2004). If considering this correlation, research institutions holding affiliation to a university may find attracting firms for the establishment of R\&D partnerships an easier task than that of their non-affiliated counterparts (Sine et al., 2003). According to Crane (1965) and Perrow (1961), a "halo effect" can increase the perceived value that buyers attribute to outputs, suggesting that institutional prestige plays an important role.

This study broadens the traditional scope in the literature and considers not only research centers with an affiliation to universities, but also independent research institutions that have their own legal status and do not have a university as their parent institution. By adopting this approach, the study aims to verify whether the attractiveness of a research institution for the establishment of an R\&D alliance owes not only to the parent institution's reputation, but also to the quality of the research of the research institution.

Specialization. Specialization is another characteristic that differentiates research institutions. Literature tackles this issue from various perspectives. One group 
of authors argues that some disciplines are more prone to accelerate researchers' activity in the form of publications and marketable inventions. Particularly, in comparison to other fields, engineering and medical-related sciences stimulate a greater capacity to generate new knowledge (Landry et al., 2007; O’Shea et al., 2008). Other studies examine the extent to which patterns of collaboration differ across different disciplines (D’Este \& Patel, 2007). Lastly, a third group of studies assesses whether the degree of academic diversification is affecting the production of research outcomes.

This study adopts this latter approach. Logic suggests that the greater the scientific dispersion (variety of knowledge fields), the greater the number of potential customers (firms); hence, scientific dispersion increases the likelihood of hiring. However, another reading points to an inverse interpretation. Because of a high degree of specialization, a research institution could more easily achieve scientific prominence within its area of expertise, thereby raising its attractiveness. Although in this case the number of firms willing to partner might be lower (because of the narrow focus), the incomes resulting from these partnerships will probably be more substantial. To gain insight into this effect, this study considers the degree of specialization of research institutions.

Infrastructures. Infrastructures include specific areas such as buildings, fixed capital equipment, and the specific area for research and promotion of knowledgetransfer results (Grimaldi \& Grandi, 2005). Research infrastructures may include laboratories, whereas knowledge transfer space can involve existing incubators for the development of in-progress ideas.

The rationale behind considering infrastructures lies in the problems that many businesses may encounter in carrying out $R \& D$ activities because these activities usually require complex and large infrastructures for product development. 
Accordingly, to save money and to take advantage not only of the expertise but also of the infrastructures, firms, and small and medium enterprises in particular, may also seek in their scientific partners accessibility to advanced equipment and spaces, facilities that otherwise would remain unaffordable because of their high costs of acquisition and maintenance. Therefore, this study suggests that research infrastructures play a role in R\&D partnerships.

\section{Method}

\subsection{Data}

TCs are important sources of knowledge and cutting-edge research developments. Aiming at closing the gap between science and industry, the Catalan Government Agency for the competitiveness of Catalan enterprises (ACCIÓ) created in 2009 the TECNIO umbrella brand, which brings together all Catalan Technology

Centers. To date, TECNIO comprises 102 TCs that work in a wide range of sectors. Figure 1 shows the geographical distribution of these centers throughout the entire Catalan territory, although the majority of them are in the surroundings of Barcelona.

Figure 1 here.

A survey containing relevant information regarding the variables of interest provides the data. Although participants returned 71 surveys, full records were only available in 56 of the instances, representing a response rate of $54.9 \%$. Data refer to year 2010.

\subsection{Method}

Because the interest of this research is not so much which factors are necessary but which combinations of factors are sufficient to explain the outcome, this study uses 
qualitative comparative analysis (QCA). QCA is particularly suitable for cases with small data samples, yet allowing the generalization of conclusions and implications to larger populations.

QCA assumes complex causality and focuses on asymmetric relationships that detect configurations that are sufficient to produce a specific outcome. A configuration is a combination of factors - conditions in QCA terminology — that is minimally necessary and/or sufficient for obtaining a specific outcome (Meyer et al., 1993). Configurations consist of conditions or factors that can be positive, negative, or absent. QCA can analyze only binary variables. Fuzzy-set qualitative comparative analysis (fsQCA) overcomes this limitation by incorporating the possibility to examine varying levels of membership of cases to a particular set. The calibration of outcomes and antecedent conditions into fuzzy sets is the first stage, thus categorizing meaningful groupings of cases (Ragin, 2008). Fuzzy-set values range from full membership (1) to full non-membership (0). The crossover point (0.5) represents neither in nor out of the set. After the calibration, the next step consists of constructing the truth table, a matrix space with $2^{\mathrm{k}}$ rows, where $k$ is the number of antecedent conditions. Each empirical case corresponds to a configuration depending on which antecedent conditions the case meets. Each column represents a condition (Fiss, 2011).

The next step is reducing the number of rows in the truth table. Although several algorithms can logically minimize a truth table, with fsQCA the most common choice is a version of the Quine-McCluskey algorithm (Quine, 1952). Using Boolean algebra, the algorithm returns a set of combinations of causal conditions, each combination minimally sufficient to produce the outcome. Row reduction depends on two criteria: coverage, which indicates the empirical relevance of a solution, and consistency, which 
quantifies the degree to which instances sharing similar conditions display the same outcome (Ragin, 2008).

For the purpose of the analysis, the outcome is the economic performance of the $\mathrm{TC}$ in terms of the income that derives from $\mathrm{R} \& \mathrm{D}$ contracts. To make income comparable across different TCs, revenues are divided by the number of customers that contracted the center in the period. Table 1 provides the full description of variables, including the details of the calibration process for both the outcome and antecedent conditions.

Table 1 here.

\section{4. $\quad$ Results}

A condition is necessary when its consistency score exceeds the threshold value of 0.9 (Schneider et al., 2010). Table 2 displays the consistency and coverage values for all antecedent conditions. As the highest consistency value among all conditions is 0.7671 , none of the variables is a necessary condition to produce the outcome.

Table 2 here.

Table 3 shows the results. Following Ragin's (2009) recommendation, this study reports the intermediate solution. Notation for the solution table Ragin and Fiss' (2008) approach. Black circles $(\bullet)$ indicate the presence of a condition, white circles $(\bigcirc)$ denote its absence, and blank cells represent ambiguous conditions.

Table 3 here.

Nine configurations of antecedent conditions occur, all of them presenting acceptable consistency indices $(\geq 0.80)$. Raw coverage indices range from 0.03 to 0.35 . This variety of recipes suggests that these nine configurations are sufficient but not necessary. Consequently, no unifying causal path explains the outcome. 


\section{Discussion}

Turning to the specific results, the presence of staff appears in five out of nine configurations. Indeed, the existence of a critical mass of researchers is important for establishing R\&D alliances. People working at TCs possess the knowledge and skills that firms are seeking, thus, human capital is a natural attractor of fruitful scienceindustry R\&D partnerships.

As for the attraction of new customers, results are imprecise. Although the presence of this condition appears in five configurations, its absence is relevant in three recipes. The underlying rationale behind this result may owe to the fact that TCs aim at establishing trustworthy relationships with knowledge-seeking partners. Because trust builds a flexible working environment that contributes to the free exchange of information, partners show a higher commitment to the agreement, higher motivation to achieve their joint goal, and higher willingness to sustain the alliance in the long term; thus resulting in the consolidation of the list of clients of a TC.

When analyzing the effect of experience, the additive effect of this factor is important in a causal recipe (either in the form of patents or papers); that is, experience always positively contributes to explaining the outcome.

As for the key hypothesis, more configurations include university-affiliated TCs than independent centers (five and two, respectively), and in configurations 8 and 9 this condition is irrelevant. This finding is consistent with previous research and supports the idea that potential firm partners may attribute value to the institutional prestige of the parent organization.

Another relevant result is the effect of specialization. Results indicate that in seven out of nine configurations, the scientific dispersion leads to high $R \& D$ contract 
income per client. This finding validates the first scenario, reinforcing the argument that if the TC operates in more than one area of knowledge, centers' hiring probabilities increase.

Contrary to the initial expectations, five recipes include the negation of area. Although infrastructures are important, their relevance lies not in their size, but in the capacity of the staff and the services TCs offer. Only in configuration number 5 does the area appear as influential. This effect occurs when specialization is important. This effect owes to the fact that TCs that concentrate their research activities in a particular field will probably need very specialized equipment to perform their daily operations, which tend to require large facilities. An example is GIRO Technology Center, which studies organic waste treatment solutions, an activity that undoubtedly demands large infrastructures.

Following Ragin's (2008) recommendation, the two causal paths with greater raw coverage (configurations 3 and 4) deserve further attention. In both cases, TCs with an affiliation to a university with a large workforce benefit from lucrative R\&D contracts with firms despite having limited infrastructures and a portfolio of regular customers. Whereas configuration number 3 presents these antecedent conditions in combination with an active publication activity in configuration number 4 , research spread compensates for the lack of experience relevance.

\section{Conclusion}

The technology strategy of a company needs to stimulate effective linkages between in-house development and external acquisition. Research institutions are knowledge-intensive organizations that are ideal partners for firms. Because science and technology must serve society, the use of science-industry collaborative R\&D 
partnerships is one of the main mechanisms by which firms gain access and acquire significant knowledge.

Aiming to better understand why some research institutions are more successful than others in establishing fruitful R\&D partnerships, this study explores how the performance of these partnerships varies with the profile of the research institution in combination with other factors: human capital, experience, and attraction capacity. The measure of performance is the income $\mathrm{R} \& \mathrm{D}$ contracts generate per client. The empirical application considers technology centers operating in the region of Catalonia that act under the TECNIO umbrella brand. The study uses fuzzy-set qualitative comparative analysis (fsQCA).

Results indicate that different causal paths explain profitable R\&D contracts. Particularly, the findings reveal that the availability of human capital, the accumulated experience (mainly papers), the capacity to attract new clients, non-specialization, affiliation to a university, and medium-sized infrastructures are sufficient conditions, because they appear in at least five of the nine configurations that result from the analysis.

Two configurations apply to the specific case of centers that have no affiliation to a university. For this type of research institution, fruitful $R \& D$ contracts take place when the TC covers different areas of expertise, has a consolidated client portfolio, and either participates actively in patenting activity or has medium-sized infrastructures.

Despite covering an existing gap in the literature, this study presents several limitations, which create opportunities for future research. First, evaluating whether the causal configurations remain static over time would be interesting. Second, although this study uses reliable antecedent conditions from the literature, future studies should consider other core factors, such as the effect of trust. Cross-country comparisons 
represent another opportunity for future studies. In this respect, future works could examine and even compare TCs in various geographies. 


\section{References}

Anderson, T. R., Daim, T. U., \& Lavoie, F. F. (2007). Measuring the efficiency of university technology transfer. Technovation, 27(5), 306-318.

Audretsch, D. B., Leyden, D. P., \& Link, A. N. (2012). Universities as research partners in publicly supported entrepreneurial firms. Economics of Innovation and New Technology, 21(5-6), 529-545.

Baba, Y., Shichijo, N., \& Sedita, S. R. (2009). How do collaborators with universities affect firms' innovative performance? The role of "Pasteur Scientists" in the advanced materials field. Research Policy, 38(5), 756-764.

Batonda, G., \& Perry, C. (2003). Approaches to relationship development processes in inter-firm networks. European Journal of Marketing, 37(10), 1457-1484.

Bruneel, J., D’Este, P., \& Salter, A. (2010). Investigating the factors diminishing the barriers to university-industry collaboration. Research Policy, 39(7), 858-868.

Chesbrough, H. (2003). Open innovation: The new imperative for creating and profiting from technology. Boston, MA: Harvard Business School Press.

Crane, D. (1965). Scientists at major and minor universities: A study of productivity and recognition. American Sociological Review, 30(5), 699-714.

D'Este, P., \& Patel, P. (2007). University-industry linkages in the UK: What are the factors underlying the variety of interactions with industry? Research Policy, 36(9), 1295-1313.

Feng, H. I., Chen, C. S., Wang, C. H., \& Chiang, H. C. (2012). The role of intellectual capital and university technology transfer offices in university-based technology transfer. The Service Industries Journal, 32(6), 899-917.

Fiss, P. C. (2011). Building better causal theories: A fuzzy set approach to typologies in organization research. Academy of Management Journal, 54(2), 393-420. 
Gray D. O. (2011) Cross-sector research collaboration in the USA: A national innovation systems perspective. Science and Public Policy, 38(2), 123-133.

Grimaldi, R., \& Grandi, A. (2005). Business incubators and new venture creation: An assessment of incubating models. Technovation, 25(2), 111-121.

Howells, J., Gagliardi, G., \& Malik, K. (2008). The growth and management of R\&D outsourcing: evidence from UK pharmaceuticals. $R \& D$ Management, 38(2), 205-219.

Kang, M., Wu, X., Hong, P., \& Park, Y. (2012). Aligning organizational control practices with competitive outsourcing performance. Journal of Business Research, 65(8), 1195-1201.

Kao, C., \& Hung, H.T. (2008). Efficiency analysis of university departments: An empirical study. Omega, 36(4), 653-664.

Kathoefer, D. G., \& Leker, J. (2012). Knowledge transfer in academia: an exploratory study on the Not-Invented-Here Syndrome. Journal of Technology Transfer, $37(5), 658-675$.

Kogut, B., \& Zander, U. (1992). Knowledge of the firm, combinative capabilities, and the replication of technology. Organization Science, 3(3), 383-397.

Kreiner, K., \& Schultz, M. (1993). Informal collaboration in R \& D. The formation of networks across organizations. Organization studies, 14(2), 189-209.

Lai, W. H. (2011). Willingness-to-engage in technology transfer in industry-university collaborations. Journal of Business Research, 64(11), 1218-1223.

Landry, R., Amara, N., \& Ouimet, M. (2007). Determinants of knowledge transfer: Evidence from Canadian university researchers in natural sciences and engineering. Journal of Technology Transfer, 32(6), 561-592. 
Laursen, K., Reichstein, T., \& Salter, A. (2011). Exploring the effect of geographical proximity and university quality on university-industry collaboration in the United Kingdom. Regional Studies, 45(4), 507-523.

Lee, J., \& Win, H. N. (2004). Technology transfer between university research centers and industry in Singapore. Technovation, 24(5), 433-442.

Lee, S. M., Ribeiro, D., Olson, D. L., \& Roig, S. (2007). The importance of the activities of service business in the economy: welcome to the Service Business. An International Journal. Service Business, 1(1), 1-5.

Liebeskind, J. P., Oliver, A. L., Zucker, L., \& Brewer, M. (1996). Social networks, learning, and flexibility: Sourcing scientific knowledge in new biotechnology firms. Organization Science, 7(4), 428-443.

Lin, J.Y. (2014). Effects on diversity of R\&D sources and human capital on industrial performance. Technological Forecasting and Social Change, 85, 168-184.

Meyer, A. D., Tsui, A. S., \& Hinings, C. R. (1993). Configurational approaches to organizational analysis. Academy of Management Journal, 36(6), 1175-1195.

Mowery, D.C., Sampat, B. N., \& Ziedonis, A. A. (2002). Learning to patent: Institutional experience, learning, and the characteristics of U.S. university patents after the Bayh-Dole Act, 1981-1992. Management Science, 48, 73-89.

Narula, R. (2001). Choosing between internal and non-internal R\&D activities: some technological and economic factors. Technology Analysis \& Strategic Management, 13(3), 365-387.

O’Shea, R. P., Chugh, H., \& Allen, T. J. (2008). Determinants and consequences of university spinoff activity: A conceptual framework. Journal of Technology Transfer, 33, 653-666. 
Odagiri, H. (2003). Transaction costs and capabilities as determinants of the R\&D boundaries of the firm: a case study of the ten largest pharmaceutical firms in Japan. Managerial and Decision Economics, 24(2-3), 187-211.

Perkmann, M., Neely, A., \& Walsh, K. (2011). How should firms evaluate success in university-industry alliances? A performance measurement system. $R \& D$ Management, 41, 202-216.

Perrow, C. (1961). Organizational prestige: Some functions and dysfunctions. American Journal of Sociology, 66(4), 335-341.

Quine, W. V. (1952). The problem of simplifying truth functions. The American Mathematical Monthly, 59(8), 521-531.

Ragin, C.C. (2009). Qualitative comparative analysis using fuzzy sets (fsQCA). In Rihoux, B., \& Ragin, C. C. (Eds.): Configurational comparative methods: Qualitative Comparative Analysis (QCA) and related techniques (pp. 87-121). Thousand Oaks, CA: Sage Publications.

Ragin, C. C. (2008). Redesigning social inquiry: Fuzzy sets and beyond. Chicago: University of Chicago Press.

Ragin, C. C., \& Fiss, P. (2008). Net effects analysis versus configurational analysis: An empirical demonstration. In Ragin, C.C. (Ed.), Redesigning Social Inquiry: Fuzzy Sets and Beyond (pp. 190-212). Chicago, IL: University of Chicago Press. 
Ribeiro-Soriano, D., \& Urbano, D. (2010). Employee-organization relationship in collective entrepreneurship: an overview. Journal of Organizational Change Management, 23(4), 349-359.

Ribeiro-Soriano, D., \& Castrogiovanni, G. J. (2012). The impact of education, experience and inner circle advisors on SME performance: insights from a study of public development centers. Small Business Economics, 38(3), 333-349.

Rivers, D., \& Gray, D. O. (2013). Cooperative research centers as small business: Uncovering the marketing and recruiting practices of university-based cooperative research centers. In Boardman, C., Gray, D. O., \& Rivers, D. (Eds.), Cooperative research centers and technical innovation (pp. 175-198). New York: Springer.

Schneider, M. R., Schulze-Bentrop, C., \& Paunescu, M. (2010). Mapping the institutional capital of high-tech firms: A fuzzy-set analysis of capitalist variety and export performance. Journal of International Business Studies, 41(2), 246266.

Sine, W. D., Shane, S., \& Di Gregorio, D. (2003). The halo effect and technology licensing: the influence of institutional prestige on the licensing of university inventions. Management Science, 49(4), 478-496.

Soh, P. H., \& Subramanian, A.M. (2014). When do firms benefit from universityindustry R\&D collaborations? The implications of firm R\&D focus on scientific research and technological recombination. Journal of Business Venturing, 29(6), 807-821.

Spithoven, A., \& Teirlinck, P. (2014). Internal capabilities, network resources and appropriation mechanisms as determinants of R\&D outsourcing. Research Policy, 44(3), 711-725 
Teirlinck, P., \& Spithoven, A. (2013). Research collaboration and R\&D outsourcing: Different R\&D personnel requirements in SMEs. Technovation, 33(4), 142-153.

Van Looy, B., Ranga, M., Callaert, J., Debackere, K., \& Zimmermann, E. (2004). Combining entrepreneurial and scientific performance in academia: towards a compounded and reciprocal Matthew-effect? Research Policy, 33(3), 425-441.

Weigelt, K., \& Camerer, C. (1988). Reputation and corporate strategy: A review of recent theory and applications. Strategic Management Journal, 9(5) 443-454.

Wilson, R. (1985). Reputations in games and markets. In Roth, A. (Ed.), Game theoretic models of bargaining (pp. 65-84). New York: Cambridge University Press.

Wolpert, J. D. (2002). Breaking out of the innovation box. Harvard Business Review, 80(8), 76-83. 
Figure 1. Geographical distribution of Catalan technology centers

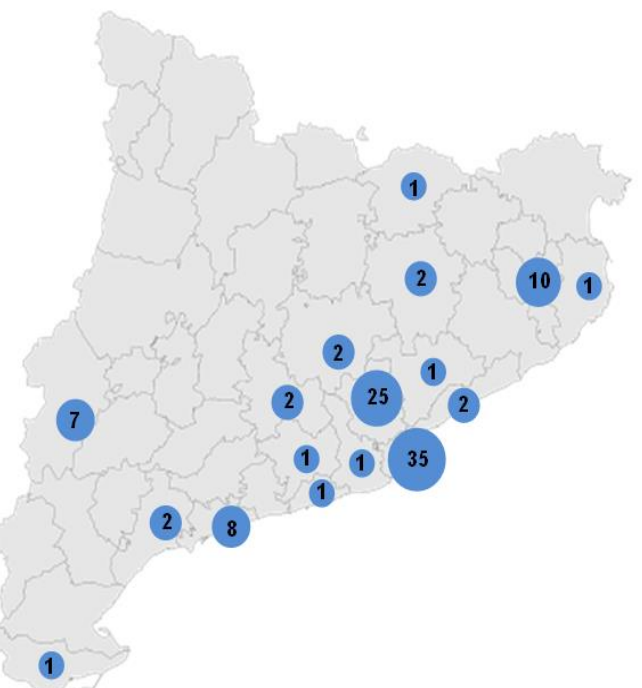

Source: Self-reported 
Table 1. Variable definition and calibration values

\begin{tabular}{|c|c|c|c|c|c|}
\hline \multirow[b]{2}{*}{ Factor } & \multirow[b]{2}{*}{$\begin{array}{l}\text { Antecedent } \\
\text { condition }\end{array}$} & \multirow[b]{2}{*}{ Description } & \multicolumn{3}{|c|}{ Membership threshold values ${ }^{\mathrm{a}}$} \\
\hline & & & $\begin{array}{l}\text { Full non- } \\
\text { members } \\
\text { hip } \\
(0.05)\end{array}$ & $\begin{array}{l}\text { Crossove } \\
\text { r point } \\
(0.5)\end{array}$ & $\begin{array}{c}\text { Full } \\
\text { membership } \\
(0.95)\end{array}$ \\
\hline $\begin{array}{l}\text { Perfor- } \\
\text { mance }\end{array}$ & Income & $\begin{array}{l}\text { Income from R\&D } \\
\text { contracts in } 2010 \\
\text { relative to the total } \\
\text { number of clients } \\
\text { during the year }\end{array}$ & $13,304.05$ & 50,962 & $351,139.39$ \\
\hline $\begin{array}{l}\text { Human } \\
\text { capital }\end{array}$ & Staff & $\begin{array}{l}\text { Total number of staff } \\
\text { (researchers) }\end{array}$ & 12 & 30.5 & 103 \\
\hline \multirow[b]{2}{*}{ Experience } & Patent activity ${ }^{\mathrm{b}}$ & $\begin{array}{l}\text { Has the TC applied } \\
\text { for any patent during } \\
2010 ?(1=y e s ; 0=\text { no })\end{array}$ & 0 & & 1 \\
\hline & Papers & $\begin{array}{l}\text { Number of papers } \\
\text { published in } \\
\text { academic journals } \\
\text { indexed in the ISI- } \\
\text { Web of Science }\end{array}$ & 0 & 4.5 & 20.5 \\
\hline $\begin{array}{l}\text { Attraction } \\
\text { capacity }\end{array}$ & New clients & $\begin{array}{l}\text { Number of new } \\
\text { clients in the year }\end{array}$ & 0 & 4.5 & 22.5 \\
\hline \multirow{3}{*}{ Profile } & Type $^{\mathrm{b}}$ & $\begin{array}{l}\text { Is the TC affiliated to } \\
\text { a university or public } \\
\text { research center? } \\
(1=\text { yes; } 0=\text { no })\end{array}$ & 0 & & 1 \\
\hline & Specialization $^{\mathrm{b}}$ & $\begin{array}{l}\text { Is the TC specialized } \\
\text { in more than one } \\
\text { area of expertise? } \\
(1=\text { yes; } 0=\text { no })\end{array}$ & 0 & & 1 \\
\hline & Area & $\begin{array}{l}\text { Area (square meters) } \\
\text { of the installations }\end{array}$ & 180 & 501 & 6500 \\
\hline
\end{tabular}

${ }^{a}$ For each antecedent condition, those observations falling in the percentile-90 are considered to represent full set membership. Percentile-10 is the threshold value for indicating full non-membership. The crossover point is defined by the median.

${ }^{\mathrm{b}}$ Variables expressed in crisp-set terms 
Table 2. Analysis of necessary conditions

\begin{tabular}{|l|c|c|}
\hline Conditions tested $^{*}$ & Consistency & Coverage \\
\hline staff & 0.6562 & 0.6484 \\
\hline$\sim$ staff & 0.6065 & 0.4648 \\
\hline patents & 0.4084 & 0.6169 \\
\hline$\sim$ patents & 0.5916 & 0.3575 \\
\hline paper & 0.6885 & 0.6656 \\
\hline$\sim$ paper & 0.5648 & 0.4403 \\
\hline newclients & 0.5416 & 0.5193 \\
\hline$\sim$ newclients & 0.7327 & 0.5752 \\
\hline type & 0.7671 & 0.4120 \\
\hline$\sim$ type & 0.2329 & 0.5118 \\
\hline specialization & 0.7948 & 0.4176 \\
\hline$\sim$ specialization & 0.2052 & 0.4960 \\
\hline area & 0.5482 & 0.5629 \\
\hline$\sim$ area & 0.7096 & 0.5283 \\
\hline
\end{tabular}

*Following the nomenclature, the symbol ( ) represents the negation of the characteristic. 
Table 3. Sufficient configurations of antecedent conditions for income

\begin{tabular}{|c|c|c|c|c|c|c|c|c|c|c|}
\hline \multirow{2}{*}{$\begin{array}{l}\text { Confi- } \\
\text { guration } \\
\text { no. }\end{array}$} & \multicolumn{7}{|c|}{ Antecedent conditions } & \multicolumn{2}{|c|}{ Coverage } & \multirow{2}{*}{$\begin{array}{c}\text { Consis- } \\
\text { tency }\end{array}$} \\
\hline & 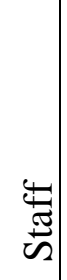 & 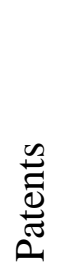 & 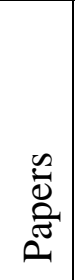 & $\begin{array}{l}\stackrel{0}{0} \\
.0 \\
0 \\
z \\
z \\
z\end{array}$ & $\underset{\leftarrow}{\stackrel{D}{\not}}$ & 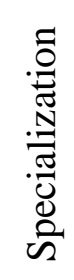 & $\stackrel{\mathscr{d}}{\stackrel{2}{Z}}$ & Raw & Unique & \\
\hline 1 & & & & $\bullet$ & 0 & - & $\mathrm{O}$ & 0.092263 & 0.032271 & 0.861004 \\
\hline 2 & 0 & $\bullet$ & & $\bullet$ & O & $\bullet$ & & 0.028548 & 0.007033 & 1.000000 \\
\hline 3 & - & & $\bullet$ & 0 & $\bullet$ & & $\bigcirc$ & 0.347124 & 0.053372 & 0.897326 \\
\hline 4 & - & & & 0 & 0 & $\bullet$ & $\bigcirc$ & 0.276789 & 0.016963 & 0.817848 \\
\hline 5 & & & $\bullet$ & $\bullet$ & $\bullet$ & $\bigcirc$ & - & 0.058337 & 0.024410 & 0.881250 \\
\hline 6 & 0 & 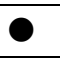 & 0 & & 0 & 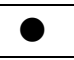 & & 0.172528 & 0.038891 & 0.937079 \\
\hline 7 & & $\bullet$ & $\bullet$ & O & $\bullet$ & $\bullet$ & $\bigcirc$ & 0.189905 & 0.061233 & 0.974522 \\
\hline 8 & $\bullet$ & & 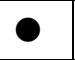 & $\bullet$ & & $\bullet$ & $\mathrm{O}$ & 0.237484 & 0.008688 & 0.860570 \\
\hline 9 & - & $\bullet$ & 0 & $\bullet$ & & 0 & & 0.116674 & 0.028134 & 0.982578 \\
\hline
\end{tabular}

Frequency threshold $=1$; consistency threshold $=0.76$. 